\title{
La máscara que luego estoy siguiendo. Sobre la relación entre cuerpo y sujeto en la obra de Erving Goffman
}

\author{
The mask that therefore I am. On the relationship between the \\ body and the subject in Erving Goffman
}

VALERIO D'ANGELO*

\begin{abstract}
Resumen. En este artículo me propongo examinar la «ambigua» relación entre cuerpo y sujeto en la obra de Erving Goffman. La teoría social del interaccionismo simbólico, en el cual generalmente se enmarca la obra de Goffman, consigue pensar una relación derivada de la subjetividad con respecto al cuerpo. El enfoque dramatúrgico devuelve al cuerpo, a la máscara y a la exterioridad un papel fundador en la construcción de uno mismo y nos obliga a cuestionar la concepción moderna del sujeto como unitario y esencialista. Procuraré entonces mostrar cómo a la base de la concepción relacional del self, está un abandono de la noción de sujeto a favor de un juego de máscaras nunca acabado.

Palabras clave: Goffman; sujeto; cuerpo; máscara; dramaturgia.
\end{abstract}

\begin{abstract}
In this article my aim is to examine the «ambiguous» relation body and subject in Erving Goffman's work. The social theory of the symbolic interactionism, in which generally Goffman's work places, manages to think a derived relation of the subjectivity from the body. The dramaturgic approach gives to the body, to the mask and to the outward appearance a founding role in the construction of oneself, and forces us to question the modern conception of the subject as an unitary essence. I will try then to show how at the basis of the relational conception of the self, lies the abandonment of the notion of subject in favour of a never-ending game of masks.
\end{abstract}

Keywords: Goffman; subject; body; mask; dramaturgy.

El hombre es menos él mismo cuando habla en su propia persona. Dale una máscara y te dirá la verdad.

Oscar Wilde

\section{Introducción. El sujeto en el interaccionismo simbólico}

El tema de la relación entre cuerpo y sujeto, y de las múltiples interacciones entre ellos, sigue sin dar descanso a sociólogos y filósofos. Un amplio abanico de planteamientos sociológicos que va desde la sociología de la vida cotidiana de Wolf (2000) a la microsociología de Ritzer (1993), desde el enfoque dramatúrgico de Joseph (1999)

\footnotetext{
Fecha de recepción: 30/05/2016. Fecha de aceptación: 27/08/2016.
}

* Investigador doctoral en la Universidad Autónoma de Madrid. 
hasta el interaccionismo simbólico de Blumer (1981), a pesar de las diferentes hipótesis teóricas y metodológicas, se ha interesado a las dinámicas, tal vez banales y mediocres, de la vida cotidiana. El estudio de la sociedad como una estructura independiente de los individuos y apriorísticamente determinada, deja el paso a una microsociología del cara a cara, que sin embargo no se deja reducir al análisis de la psicología individual. El interaccionismo simbólico se presenta pues como alternativa tanto al estructuralismo, que veía la conducta de los individuos como determinada enteramente por las grandes estructuras ideológicas, económicas, sociales, etc., como a la psicología conductista, que explicaba la acción social únicamente en términos de elecciones individuales. El objeto de análisis del interaccionismo simbólico es en cambio la situación, esto es, la mediación del sujeto con el contexto social en el cual opera. Ella, igual que los «juegos de lenguaje» del segundo Wittgenstein (2007), es el marco al interior del cual emerge el sentido que los individuos otorgan a sus acciones y al mundo circunstante. El significado, dicho de otra forma, emerge a través de la acción diaria de individuos en una relación de interacción cualquiera, cotidiana. Los mismos casos de observación de algunos interaccionistas son precisamente situaciones de las más corrientes: los peatones en una calle, la gente en cola al supermercado, amigos charlando en el bar etc. En todos estos casos, la sociedad es producida y re-producida por las acciones diarias de los individuos. Y sin embargo, como veremos en este escrito, el mismo estatus de sujeto es algo problemático desde la perspectiva interaccionista. Él no es totalmente libre ni respecto a sus acciones ni respecto a su identidad, que tiene que ser constantemente negociada con los demás sujetos. Georges Herbert Mead hace especial hincapié en el carácter relacional del sujeto. Gran conocedor de Hegel, Mead afirma que:

el todo (la sociedad) es anterior a la parte (el individuo), no la parte al todo; y la parte es expresada en términos del todo, no el todo en términos de la parte o las partes (Mead, 1993, 39).

Sin embargo, esto no significaba que Mead considerase la acción individual cómo una mera re-producción de la acción de la estructura, y el sujeto un mero producto de ella. El «sí mismo» (self), según Mead, emerge como sujeto sólo en la medida en que es capaz de «objetivarse», es decir, de ser reconocido por los demás en cuanto sujeto. Según Alex Honneth: «Mead invierte la relación del yo y del mundo social y afirma la primacía de la percepción de los otros respecto al desarrollo de la conciencia de sí» (Honneth, 1997, 95). Por lo tanto, el sujeto no es una conciencia auto-centrada y autónoma, precedente a la interacción social (como querría la psicología conductista), pero tampoco es únicamente fruto de un proceso de socialización total (como querría un estructuralismo rígido). El self es producto y a la vez productor de la situación de interacción. Él se convierte en sujeto cuando finalmente adopta la mirada del otro (el «Otro generalizado» decía Mead). A esto se refiere el autor cuando dice que:

No podemos realizarnos a nosotros mismos sino en el grado en que reconocemos al otro en su relación con nosotros. Sólo cuando adopta la actitud del otro, puede el individuo realizarse a sí mismo como persona (Mead, 1993, 168) 
Una vez formado, el self es independiente del contacto (y del contrato) con la sociedad, ya que él o ella es capaz de «entablar una interacción consigo mismo, interpelándose, respondiendo a la interpelación e interpelándose de nuevo» (Blumer, 1981, 46-47). También Herbert Blumer (que acuñó el término interaccionismo simbólico), igual que Mead, esfuma la dicotomía individuo/sociedad, equiparando el self con el Otro de la sociedad. El sentido emerge, para Blumer, en la gramática social, entendida como el conjunto de reglas sintácticas que posibilitan la comprensión del sentido mismo. La transmisión de sentido está pues en las manos de los propios hablantes y no podría haber esta transmisión sin una participación activa de los hablantes. Es este un aspecto ignorado tanto por el psicologismo conductista, con su énfasis en la voluntad individual, como el estructuralismo, con su ceguera acerca del rol del individuo. En conclusión, para los interaccionistas, la interacción social es más primitiva que la autoconciencia. Esta se afirma tras la interacción con los demás. El sujeto mismo es puesto en tela de juicio, y Erving Goffman es sin duda alguna uno de los autores que más ha contribuido a ello.

\section{Erving Goffman y el enfoque dramatúrgico}

Goffman, el «inventor de lo infinitamente pequeño», como hubo a llamarlo una vez Pierre Bourdieu (Bordieu, 1982, 3) es tal vez el teórico que mejor supo cuestionar la noción moderna de sujeto, como conciencia unitaria, uniforme y coherente. En su lugar, el self, tal y como lo describe Goffman, es un sujeto plural y dividido en los múltiples roles que desempeña a diario. Adentrémonos en el asunto.

El enfoque de Goffman también es conocido como «enfoque dramatúrgico», ya que el teatro sirve de metáfora para describir la acción social. En un espacio de interacción, el self escenifica un papel ante una audiencia con la finalidad de convencerla de su actuación. Todo, en el estudio de Goffman, remite al teatro: actores, escena, ensayo de roles, equipo escénico, bastidores, etc., así como se desprende de su primer libro, La presentación de la persona en la vida cotidiana (1959), sacado de su tesis doctoral. Aquí Goffman describe (sobre todo tomando como caso de análisis un hotel de las islas canadienses Shetland), aquella serie de conductas diarias, voluntarias e involuntarias, a través de las cuales los actores proyectan una definición de una situación determinada, procurando que la actuación resulte lo más convincente posible. Vemos que aquí Goffman privilegia la noción elástica de actuación a aquella, más rígida y de corte funcionalista, de «rol social», que deja poco margen de elección al individuo (aunque Goffman abandone finalmente este planteamiento en los trabajos más maduros como Frame Analysis, de 1974, donde verá una más decidida conformidad con el «rol social»). Ahora bien. Igual que Mead, al cual se remite explícitamente, también Goffman subraya que toda definición de sí, es siempre una definición mediada por la situación, esto es, por la presencia de los demás. Como en Mead, también en Goffman el self recibe su reconocimiento por los otros, aunque el autor canadiense «amplíe» este concepto, llegando a ver en los demás literalmente todos aquellos que ocupan y comparten con el actor las varias escenas diarias (tal y como resultará evidente en Relaciones en Público, de 1979)12:

1 Notamos un desplazamiento de finalidad en Goffman. De hecho, si en un principio (La presentación de la persona en la vida cotidiana) el objetivo es lo de definir la situación, el Goffman posterior (Relaciones en Público) 
Nuestro guía debe ser George Herbert Mead. Lo que el individuo debe ser para sí mismo no es algo que se ha inventado él. Es lo que sus otros importantes han llegado a entender que debe ser él, lo que han llegado a tratarle como si fuera, y la forma en que, en consecuencia, debe tratarse él si ha de relacionarse con las relaciones de ellos con él. Mead sólo se equivocó al creer que los únicos otros pertinentes son los que se preocupan de prestar una atención sostenida y clara al individuo [...] lo que el individuo en parte debe llegar a ser para sí mismo es alguien cuyas apariencias sus otros pueden entender como normales (Goffman, 1979, 277).

De hecho, ver el self como un efecto dramático, «un producto de la escena representada, y no una causa de ella» (Goffman, 1997, 269), lleva a una re-definición del lugar de las apariencias en la creación del self mismo. En pocas palabras, Goffman está interesado en cómo el actor consigue re-presentar un personaje que sea creíble para la audiencia. Por esto pasa a analizar aquella serie de técnicas que permiten al individuo encarnar con éxito un rol. La primera y más fundamental de estas técnicas es, nos dice, el mantenimiento de la «fachada» (front). Esta es la dotación expresiva, como el vestido, el lugar, el decorado, etc., que el actor procura cuidadosamente controlar. Aunque no siempre pueda manejar todos los elementos de la actuación (por ejemplo la elección del escenario o el reclutamiento de los actores), puede sin embargo pilotar los otros factores (como la vestimenta o la mismísima propuesta de la situación) para influir con la mayor precisión posible sobre el público. En Behavior in Public Places (1963), Goffman describe esta primera, primordial y más importante fase de auto-gestión de la persona, que funciona como «instrumento de comunicación». Es decir, la definición de la situación que el sujeto propone a los demás actores, se halla «incorporada» en su persona. Por ello, la primera regla situacional consiste en la «gestión disciplinada de la propia apariencia o fachada personal» (Goffman, 1963, 27), con la finalidad de presentar una identidad creíble a los demás. Del buen uso de los elementos expresivos, o sea del cuidado de la fachada, depende el éxito de la performance. Sin embargo hay contextos, como las cárceles y los hospitales psiquiátricos (que Goffman llama «instituciones totales») donde el preso se ve privado de este «derecho a la máscara». En Internados (1970a) y Estigma (1993) Goffman estudia estos mecanismos a través de los cuales el interno se ve despojado de su capacidad de re-presentación, de su posibilidad de presentar una definición de si y de la situación. Todos los procedimientos penitenciarios, como el registro de la ropa, el control del correo personal, los monos idénticos, etc., apuntan precisamente a mutilar la capacidad del interno de negociar respecto a su identidad (Goffman, 1970a, 31) o, para decirlo en otras palabras, de decidir acerca de su máscara. El interno pues se ve privado del derecho de mantener un determinado orden expresivo, perdiendo la facultad de crearse una identidad.

Ahora bien. En una situación corriente de interacción, esta práctica de escenificación y mantenimiento se basa, según el autor, en una pragmática precisa: el ritual ${ }^{2}$. Este concepto,

define esta finalidad como la de ser normales, presentable a los ojos de los demás, y entonces cumplir con una serie de obligaciones sociales. Sin embargo esto no interesa para el objetivo de este escrito, ya que a pesar de este desplazamiento, Goffman no abandona, sino que tal vez acentúa, su enfoque dramatúrgico.

2 La atención para el ritual ha estado presente en los trabajos de Goffman desde el principio, pero ha sido objeto especial de estudio en Ritual de la interacción (1970b). 
creado por Durkheim (1991), adquiere en Goffman un sentido diferente. Como es sabido, para el primero el ritual era la escenificación del orden simbólico que brindaba a la audiencia primitiva los códigos morales que regulaban la relación entre lo sagrado y lo profano. El orden social profano, de por sí anómico, estaba sustentado y regido por un universo sagrado, que constituía un cosmos ordenado y dotado de sentido ${ }^{3}$. El ritual tenía pues la función de recordar, re-presentándolo, el orden primordial del cosmos. Goffman quita al ritual este halo místico y ve en ello una parte constitutiva de la vida diaria del ser humano. El ritual ordena los actos y los gestos de la vida diaria, y tiene por finalidad de conformar las vivencias cotidianas a los roles aceptados socialmente. Pero, igual que Durkheim, también Goffman ve la finalidad del ritual en mantener el orden social establecido. Asimismo, para Goffman también, el ritual tiene la función de reunir una vasta audiencia alrededor de creencias compartidas. Sin embargo, en las sociedades fragmentadas y secularizadas del siglo XX, ya no hay creencias universales compartidas por todos; y a pesar de todo, la sociedad occidental sigue guardando un elemento sagrado: el individuo. Este es el objeto sagrado que los rituales quieren proteger:

Empleo el término ritual porque me refiero a actos por medio de cuya componente simbólica el actor muestra cuán digno de respeto o cuán dignos son los otros de ese respeto [...] La cara de uno, entonces, es una cosa sagrada, y por lo tanto el orden expresivo necesario para sostenerla es de orden ritual. (Goffman, 1970b, 25)

El self, en pocas palabras, se re-presenta a través de los rituales de la vida diaria. Todas las expresiones que el sujeto adopta en la vida diaria (gestos, rostros, etc.) están orientadas por códigos rituales que apuntan a «salvar la cara» y ayudar a los demás a hacer otro tanto. La etiqueta y la forma, ritualizadas a diario, protegen la autodefinición de la identidad (como el no tocar, durante una conversación, temas que puedan amenazar la concepción del yo de los participantes).

De lo dicho hasta ahora, se intuye ya el papel decisivo del cuerpo en este proceso de formación del self. El ritual actúa sobre el cuerpo y se transmite a través de ello, y no podría haber ritualistica sin un determinado uso del cuerpo, que por lo tanto se convierte en «un producto de acción e interacción en los encuentros sociales situados. En la acción comunicativa el cuerpo llega a ser» (Vannini, 2006, 6). El ritual, en pocas palabras, tiene curso «haciéndose cuerpo», en el dominio del gesto, en la manifestación de las emociones, y más en general en todas aquellas posturas que el actor usa a diario para presentar una actuación convincente. El papel del cuerpo es entonces doble. Si por un lado este es vehículo de información y medio a través del cual se quiere comunicar una determinada definición de la situación a los demás, por el otro es ya un producto social y sirve para mantener el orden moral dominante (Brisset y Edgley, 1990, 3). En ambos casos, el cuerpo se halla insertado en un entramado de relaciones sociales que hacen de él, más bien que

3 Dice por ejemplo Durkheim: «Los ritos son, ante todo, los medios a través de los cuales el grupo social se reafirma periódicamente y se constituye como una comunidad moral» (Durkheim, 1991, 394). A pesar de las diferencias acerca del entendimiento del ritual en los dos autores, tanto para Goffman como para Durkheim, el ritual implica tres elementos: la presencia de un auditorio; un foco de atención a partir del cual se generan emociones compartidas entre el público y los actores; acciones que tengan una finalidad simbólica y no práctica. 
una posesión del sujeto, un objeto de negociación social. La antropología de corte estructuralista confirma esta intuición acerca del cuerpo. Mary Douglas por ejemplo distingue entre el cuerpo físico y el cuerpo social, afirmando que las exigencias del primero «no sólo se subordinan a las exigencias sociales, sino que se consideran contrarias a estas últimas» (Douglas, 1988, 97). El cuerpo está moldeado por las fuerzas sociales que limitan su modo de expresión a patrones bien definidos. Este está sujeto al control social, y sus funciones revelan el grado de rigidez de la estructura social. Así, dice Douglas, en la sociedad occidental, a un grado mayor de jerarquización social y restricciones culturales, corresponde un mayor grado de de-corporeización del cuerpo (menos ruido al comer, menos masticación, más modulación en la risa, etc.). Douglas, igual que Goffman, no separa netamente la función del cuerpo como transmisor y del cuerpo como receptor, de hecho, el cuerpo siempre se expresa simbólicamente y de esta manera transmite información sobre la situación (en una ocasión muy formal por ejemplo, el cuerpo transmitirá información sobre la situación en cuanto ya estará encorsetado en los estrictos límites de la etiqueta). Pero mientras Douglas hace del cuerpo una especie de modelo en miniatura de la estructura social, donde «lo que se grava en la carne humana es una imagen de la sociedad» (Douglas, 1991, 134), en Goffman el cuerpo dramatúrgico es un objeto «en construcción» y en perpetua negociación entre el individuo y la sociedad. El cuerpo se adapta y se moldea en una serie de rituales, de los cuales depende una imagen del sí mismo, esto es, el reconocimiento de la identidad.

\section{Mascara e identidad}

Según acabamos de ver, el cuerpo es decisivo para el mantenimiento de una cierta presentación del self. En el espacio de interacción, el individuo asume un rol a través del uso de su dotación expresiva. Las informaciones que el individuo desea ocultar, así como aquellas que en cambio desea transmitir, dependen de los rituales corporales. De la buena gestión del cuerpo, repitámoslo una vez más, depende la formación o el mantenimiento del self. Goffman es consciente de que no todas las informaciones son expresivas, ya que una parte significativa de ellas son adscritas (como la raza, el género, la altura, etc.). Aun así, también estas características naturales, tienen que ser escenificadas y cita Simone de Beauvoir, cuando describe cómo las mujeres se vuelven mujeres, comportándose como mujeres, esto es representando un rol$^{4}$. Goffman llama embodiment este proceso, por el cual el objeto-cuerpo es activamente experimentado, producido, sostenido y transformado como sujeto-cuerpo. La formación de la subjetividad, si quisiéramos simplificar, es ante todo un proceso de «encarnación», de experimentación y expresión corporal. En la realización del sujeto no hay ningún repliegue hacia la interioridad y los meandros de la con-

4 «Y aunque cada cual se vista de acuerdo con su condición, también estamos ante un juego. EI artificio, como el arte, se sitúa en lo imaginaria. EI cuerpo y el rastro no solo se hallan disfrazados por la faja, el corpiño, las tinturas y los maquillajes, sino que la mujer menos sofisticada, una vez que se ha «arreglado», no se propone a la percepción: como el cuadro o la estatua, o el actor en el escenario, es un análogo a través del cual se sugiere un objeto ausente que es su personaje, pera que ella no es. La halaga esa confusión con un objeto irreal, necesario y perfecto como un de novela, un retrato o un busto, y se esfuerza por imaginarse en él, y presentarse de ese modo ante si misma petrificada y justificada» (De Beaouvoir, 1953, 533 cit. en Goffman, 1997, 66-67). 
ciencia, sino un movimiento hacia una externalización simbólica. Bryan Turner, hablando del cuerpo como un vehículo de significado, afirma que ello:

tiene que ser constantemente y sistemáticamente producido, sostenido, y presentado en la vida diaria y entonces el cuerpo es [...] realizado y actualizado a través de toda una variedad de actividades o prácticas sociales reguladas (Turner, 1984, 24).

Esta noción de producción del cuerpo, lo libera de su calidad de dato, de objeto de decisión por parte del individuo o de la sociedad. Ello es siempre una mediación y negociación. En definitiva, en la perspectiva del interaccionismo simbólico, nosotros no tenemos un cuerpo sino que creamos un cuerpo, que «adquiere sentido» sólo en el acto de hacerse, esto es, de representarse.

Este entendimiento del cuerpo lleva a un re-pensamiento de la noción de sujeto. De hecho, según hemos argumentado, el self se hace en el curso de la acción dramática: él o ella presenta, a través de un uso voluntario e involuntario del cuerpo, una definición de la situación. También vimos que una actuación exitosa es aquella que consigue convencer a la audiencia de su veracidad. Una manifiesta y garrafal incoherencia entre la identidad que se quiere proponer, y un determinado uso del cuerpo, lleva el individuo a la pérdida de su máscara, esto es, al desconocimiento por parte de los demás de la identidad que a este individuo se le había prestado. ¿Estando así las cosas, sigue teniendo sentido hablar de un sujeto precedente a la acción dramática? Y sobre todo ¿puede haber un sujeto precedente al cuerpo y decisor de su estatus? Evidentemente no. Es cierto más bien lo contrario, como señala justamente Manuel Delgado:

el cuerpo ha visto reducida su función a la de vehículo sustantivo de la subjetividad y $[\ldots]$ no se ha reconocido la posibilidad de que el cuerpo no sea en realidad el resultado sino la fuente misma de esa subjetividad, el lugar sobre cuya superficie un orden socio-espacial determinado inscribe sus demandas y materializa sus discursos (Delgado, 2006, 113-114).

El espacio de la interacción es el espacio donde «el cuerpo en tanto que objeto no puede ser separado del cuerpo como sujeto; ellos proceden el uno del otro» (Waskul y van der Riet, 2002, 510). En conclusión: el interaccionismo simbólico nos reta a dejar de lado la noción tradicional de sujeto (centrado, autónomo) y a re-configurarlo a la luz de sus relaciones, y especialmente de las relaciones más superficiales, según Goffman. Es aquí, en un espacio de interacción, donde un sujeto viene a la luz. De hecho, si el self, para repetir las palabras de Goffman, es un producto de la escena dramática, su identidad es siempre precaria y sujeta a cambios. Decíamos hace poco que la máscara que la sociedad le ha entregado al individuo, le puede ser retirada en cualquier momento si no demuestra ser «digno» de ella. El self está entonces siempre, por así decirlo, amenazado por una espada de Damocles en su subjetividad. Siendo él un producto de la interacción dramática, su estabilidad puede peligrar en cualquier momento. Está claro entonces que el sujeto, unitario y esencialista pensado por la filosofía moderna, pierde su integridad y se fragmenta en las múltiples situaciones diarias donde se desenvuelve la vida del individuo. Con esto, el interaccionismo consigue 
emanciparse «del subjetivismo y de las fenomenologías de la intersubjetividad» (Joseph, 1999, 60), de toda visión esencialista del sujeto que valoraba una supuesta «autenticidad» del mismo. La teoría interaccionista se deshace del mito de la interioridad (Bouveresse, 1976), enfatizando por el contrario las calidades dramatúrgicas del individuo, esto es, su habilidad de poner en escena un rol a través de las apariencias, de la superficie, de la máscara. La autenticidad entonces, no significa ser «uno mismo» y elegir una máscara que mejor se adapte al «verdadero yo», sino ser capaces precisamente de mantener la máscara. En lugar de uno, hay una pluralidad de sujetos o, como dice Joseph, el yo «no se individualiza sino dividiéndose» (Joseph, 1999, 25). El uso del plural para referirse a la subjetividad es aquí obligatorio: el individuo se subjetiva en una pluralidad de sujetos, dividiéndose según las circunstancias 5 . Goffman hace claramente hincapié en este aspecto, citando a Ezra Park:

«Probablemente no sea un mero accidente histórico que el significado original de la palabra persona sea máscara. Es más bien un reconocimiento del hecho de que, más o menos conscientemente, siempre y por doquier, cada uno de nosotros desempeña un rol... Es en estas roles donde nos conocemos mutuamente; es en estos roles donde nos conocemos a nosotros mismos» (Goffman, 1997, 31)

Lo cual implica aceptar que quizás no haya nada tras las distintas máscaras que utilizamos constantemente en nuestra vida diaria.

\section{Conclusión}

En este escrito hemos procurado esclarecer la relación entre cuerpo y sujeto en el interaccionismo simbólico, y sobre todo en la obra de Erving Goffman. Hemos visto que el interaccionismo devuelve al cuerpo un papel importante, casi decisivo, en la formación del sujeto. El propio Goffman sintetiza magistralmente esta importancia del cuerpo, de la superficie, de la máscara, en la creación del individuo: «la naturaleza más profunda de un individuo no va mucho más allá de la piel, de la espesura de la piel de sus otros» (Goffman, 1979, 354). Y sin embargo hay un tema, que Goffman tal vez no profundizó lo suficiente, y que podría ser el punto de partida de futuras investigaciones: la «distancia de rol» ${ }^{6}$. El buen actor, afirmaba Goffman, es aquel que sabe distanciarse de su rol, introduciendo un elemento de disonancia en el rol (como el cirujano que cuenta un chiste durante una operación peligrosa, o el empleado de la limpieza que hace su trabajo sin ganas). Pero interpretar la distancia de rol como simple nonchalance, significa pasar por alto la cuestión del quién realiza esta distancia y, de ahí, de si haya un «verdadero sujeto» detrás de las múltiples fachadas que el individuo encarna a diario. En el ensayo sobre la distancia de rol, Goffman «descubre» la parte sagrada de la persona, donde el individuo se revela a los seres queridos

5 Mead fue tal vez el primero en ver esta característica del sujeto interaccionista: «El proceso social mismo es el responsable de la aparición de la persona; esto no existe como una persona aparte de ese tipo de experiencia. Una personalidad múltiple es en cierto sentido normal. (Mead , 1993, 174)».

6 Escribe Goffman al respecto: «Asumir un rol significa desaparecer completamente en el sí mismo virtual elaborado por la situación, exponerse a la percepción de otros mediante la propia imagen y confirmar expresivamente la propia aceptación de ella. Asumir un rol significa ser subsumido por éste» (Goffman, 1961, 106). 
por lo que realmente es una vez se haya quitado todas las capas sociales. Como ha observado James Chriss, esto puede significar que la distancia de rol no es una opción en la parte sagrada, donde una persona aparece en su autenticidad. Pero, nota Chriss, Goffman pasa la mayoría de su ensayo demostrando cómo la distancia de rol se manifiesta no solo en las áreas profanas de la vida social, sino también en las sagradas. Lo cual deja suponer que no existe un yo auténtico, libre de las máscaras sociales. Por otro lado, no hay que olvidar que Goffman diseña un «modelo mínimo de actor», que pero en todo caso sigue estando detrás del personaje y le da, literalmente, forma. Sin embargo, la posibilidad es barajada entre líneas por el mismo autor cuando recomienda que, para poder comprender la acción social, «sería preferible partir del exterior del individuo y trabajar hacia adentro en lugar de partir de su interior y trabajar hacia afuera (Goffman, 1997, 92). Queda por descubrir cuál es este interior.

\section{Bibliografía}

Blumer, H. (1981), El Interaccionismo simbólico, Madrid, Hora.

Bourdieu, P. (1982), «Goffman, le découvreur de l'infiniment petit», en Le Monde, 4 de Diciembre.

Bouveresse, J. (1976), Le Mythe de l'Interiorité: Expérience, Signification et Langage Privé chez Wittgenstein, Paris, Les Editions Minuit.

Brissett, D., y C. Edgley, (1990), Life as Theater: A Dramaturgical Sourcebook, New York, Aldine.

Delgado, M. (2006), «Tránsitos. Espacio público, masas corpóreas», pp. 113-132 en OrtízOses A. y P. Lanceros (eds.), La Interpretación del Mundo, cuestiones para el tercer milenio, Barcelona y México, Anthropos/Universidad Autónoma Metropolitana.

Douglas, M. (1988), Símbolos naturales, Madrid, Alianza.

Durkheim, E. (1991), Las formas elementales de la vida religiosa, México, Editorial Colofón.

Foucault, M. (2009), Vigilar y castigar, Madrid, Siglo XXI.

Goffman E. (1961), Encounters, Two studies on the sociology of interaction, Indianapolis, Bobbs-Merill.

Goffman, E. (1963), Behavior in Public Places. Notes on the Social Organization of Gatherings, Glencoe, Macmillan.

Goffman, E. (1970a), Internados: Ensayos sobre la situación social de los enfermos mentales, Buenos Aires, Amorrutu.

Goffman, E. (1970b), Ritual de la interacción, Buenos Aires, Editorial Tiempo Contemporáneo.

Goffman, E. (1979), Relaciones en público. Microestudios de orden público, Madrid, Alianza.

Goffman, E. (1993), Estigma. La identidad deteriorada, Buenos Aires, Amorrutu.

Goffman, E. (1997), La presentación de la persona en la vida cotidiana. Buenos Aires, Amorrortu.

Honneth, A. (1997), La lucha por el reconocimiento, Barcelona, Grijalbo Mondadori.

Isaac, J. (1999), Erving Goffman y la microsociología, Barcelona, Gedisa. 
Mead, G.H. (1993), Espíritu, persona y sociedad: desde el punto de vista del conductivismo social México/Buenos Aires/Madrid, Paidós.

Ritzer, G. (1993), Teoría sociológica contemporánea. Madrid, McGraw-Hill Interamericana.

Turner, B. (1984), The Body and Society: Explorations in Social Theory, Oxford, Basil Blackwell.

Vannini, P. (2006), Body/Embodiement. Simbolic interaction and the sociology of the body. Londres, Routledge.

Waskul, D., y P. van der Riet (2002), «The Abject Embodiment of Cancer Patients: Dignity, Selfhood, and the Grotesque Body.» Symbolic Interaction, 25 (4):487-513.

Wittgenstein, L. (2007), Tractatus Logico-philosophicus, Madrid, Alianza.

Wolf, M. (2000), Sociologías de la vida cotidiana. Madrid, Cátedra. 